\title{
Components and Tidal Modulation of the Wave Field in a Semi-Enclosed Shallow Bay
}

Lukas WinklerPrins ${ }^{1 *}$ (lukas_wp@berkeley.edu)

John L. Largier ${ }^{2}$

Ana Vila-Concejo ${ }^{3}$

Shari L. Gallop ${ }^{4,5}$

Thomas E. Fellowes ${ }^{3}$

Maryam Rahbani ${ }^{3,6}$

[1] University of California, Berkeley; Civil \& Environmental Engineering; [2] University of California, Davis; Bodega Marine Laboratory; [3] Geocoastal Research Group, The University of Sydney, Sydney, Australia; [4] School of Science, University of Waikato, Tauranga, New Zealand; [5] Environmental Research Institute, University of Waikato, Hamilton, New Zealand; [6] Department of Marine Science and Technology, University of Hormozgan, Bandar Abbas, Iran

This manuscript has been submitted for publication in ESTUARIES AND COASTS. The pre-print manuscript here in EarthArXiv has yet to be formally accepted for publication, and has not yet been subject to peer-review. Subsequent versions of this manuscript may have slightly different content. If accepted, the final version of this manuscript will be available via the "Peer-reviewed Publication DOI" link on this webpage. Feel free to contact the authors; we welcome feedback. 


\section{Components and Tidal Modulation of the Wave Field in a Semi-Enclosed Shallow Bay}

${ }_{4}$ Lukas WinklerPrins $^{1 *}$, John L. Largier ${ }^{2}$, Ana Vila-Concejo ${ }^{3}$, Shari L. Gallop ${ }^{4,5}$, 5 Thomas E. Fellowes ${ }^{3}$, Maryam Rahbani ${ }^{3,6}$

*For correspondence: lukas_wp@berkeley.edu (LWP)

- ${ }^{1}$ University of California, Berkeley; Civil \& Environmental Engineering; ${ }^{2}$ University of 7 California, Davis; Bodega Marine Laboratory; ${ }^{3}$ Geocoastal Research Group, The \& University of Sydney, Sydney, Australia; ${ }^{4}$ School of Science, University of Waikato, - Tauranga, New Zealand; ${ }^{5}$ Environmental Research Institute, University of Waikato, 10 Hamilton, New Zealand; ${ }^{6}$ Department of Marine Science and Technology, University of 11 Hormozgan, Bandar Abbas, Iran

12

13

14

\section{Abstract}

The wave field in coastal bays is comprised of waves generated by far-off storms and waves generated locally by winds inside the bay and regionally outside the bay. The resultant wave field varies spatially and temporally and is expected to control morphologic features, such as beaches in estuaries and bays (BEBs). However, neither the wave field nor the role of waves in shaping BEBs have been well-studied, limiting the efficacy of coastal protection and restoration projects. Here we present observations of the wave field in Tomales Bay, a $20 \mathrm{~km}$ long, narrow, semi-enclosed embayment on the wave-dominated coast of Northern California (USA) with a tidal range of $2.5 \mathrm{~m}$. We deployed pressure sensors in front of several beaches along the linear axis of the bay. Low-frequency waves $\left(4 * 10^{-2}-2.5 * 10^{-1} \mathrm{~Hz}\right.$ or $4-25 \mathrm{~s}$ period) dissipated within $4 \mathrm{~km}$ of the mouth, delineating the "outer bay" region, where remotely-generated swell and regionally-generated wind waves can dominate. The "inner bay" spectrum, further landward, is dominated by fetch-limited waves generated within the bay with frequency $\geq 2.5 * 10^{-1} \mathrm{~Hz}$. The energy of both ocean waves and locally-generated wind waves across all sites were modulated by the tide, owing to tidal changes in water depth and currents. Wave energies were typically low at low tide and high at high tide. Thus, in addition to fluctuations in winds and the presence of ocean waves, tides exert a strong control on the wave energy spectra at BEBs in mesotidal regions. In general, it is expected that events that can reshape beaches occur during high wind or swell events that occur at high-tide, when waves can reach the beaches with less attenuation. However, no such events were observed during our study and questions remain as to how rarely such wind-tide concurrences occur across the bay.

Keywords - s heltered beach, low-energy beach, shallow-water waves, spectral analysis, wind waves

\section{Introduction}

Beaches in estuaries and bays (BEBs) are widespread throughout the world, yet many questions remain as to the dominance of various forces on their geomorphology and stability (Jackson et al., 2002). Beyond geologic controls, BEB dynamics are a product of wave activity, much like for openocean beaches. However, due to the persistent lack of ocean swell energy, periodic local storm 
events (Gallop et al., 2020b) and other mechanisms (such as tidal currents, surge, or infragravity waves) may play larger morphologic roles than on open coast beaches (Vila-Concejo et al., 2020). Additionally, waves that cause morphologic change to BEBs may only occur at particular water levels, based on tidal stage or river outflow (Eliot et al., 2006).

The wave field inside an embayment is a combination of both locally-generated waves and those that enter from the ocean. Local wave production inside bays is often limited by fetch Vackson et al. (2002)), while longer-period ocean-originating waves are generally dissipated as they enter through the mouth. As waves of all frequencies travel through an embayment, they are subject to a variety of forces that modify the water surface spectra, including refraction, diffraction, dissipation by bottom friction, and interactions with currents (Davidson et al., 2008). The effect of bottom friction on waves is inversely related to water depth as they travel over shallows and may drive nonlinear interactions between different parts of the spectrum (Zhu et al., 2020). Additionally, tidal currents interact with waves and contribute to bulk transport Davidson et al. (2008). Thus, there are tidal timescales relevant to the wave energy delivered to the shore.

The relative importance of ocean-originating waves versus local waves varies spatially and temporally in response to various controls. In this paper, we use surface wave spectra to quantify the wave fields at four pressure sensors installed offshore of beaches inside Tomales Bay, California, whose linear geometry is in-line with the dominant wind direction. We delineate the drivers of wave motion across three ranges of frequencies, corresponding to locally-generated wind waves, ocean swell, and infragravity motions. We thus address four objectives: (1) to investigate the dominance of wind chop in the bay; (2) to establish how far swell and infragravity waves penetrate past the mouth; (3) to examine how tidal stage and currents affect the combined wave field; and (4) to explore the beach-building implications of the observed wave fields.

\subsection{Regional Context}

Tomales Bay is a long, shallow embayment on the northern California coast, USA (Fig. 1), approximately $20 \mathrm{~km}$ long, $2 \mathrm{~km}$ wide, and only $6 \mathrm{~m}$ deep on average, although a channel of up to $18 \mathrm{~m}$ deep persists near the mouth (Anima et al., 2008). The bay is a near linear rift valley of the San Andreas Fault, which runs the length of the bay, delineating the boundary between the Pacific and North American plates, aligned approximately $320^{\circ}$ from north.

Weather patterns in the area follow a Mediterrannean climate with a dry summer and fall and wet winter and spring. Our study period, September-November 2019 had no rain events. Winds during this storm-free period were dominated by a daily sea breeze of afternoon onshore winds and evening or early-morning calm. The summer wave climate is mostly northwest wind swell, with some long-period south or southwesterly swells arriving from the south Pacific. In the winter, storms in the north Pacific deliver larger and longer-period waves from the northwest.

Inside Tomales Bay, there are many sandy beaches which are "low-energy," in line with the characterization by Jackson et al. (2002); they are subject to small wave heights and rare local storm events in the rainy season. These beaches are generally small ( $<300 \mathrm{~m}$ in length, typically $<15 \mathrm{~m}$ in width) pocket beaches between rocky outcrops or headlands. Sediment inputs include small, steep watersheds on both sides of the bay, and Lagunitas Creek (at the head of the Bay) and Walker Creek (Fig. 1) which contribute mostly fine sand and coarse silt (Anima et al., 2008). Tides in Tomales Bay are semi-diurnal with $1.76 \mathrm{~m}$ between mean higher-high and mean lower-low water NOAA (2020), and the data recorded during our study period reflected this.

\section{Methods}

\subsection{Sensor Deployment}

RBRsolo ${ }^{3} \mathrm{D}$ sensors recording continuously at $2 \mathrm{~Hz}$ were installed at Lawsons Landing, Seal Beach, Pelican Point, and Tomasini Point (locations hereafter named S1, S2, S3, and S4, respectively) (Figure 1). S4 was deployed on 29 August, the other three on 27 September 2019. All four were re- 


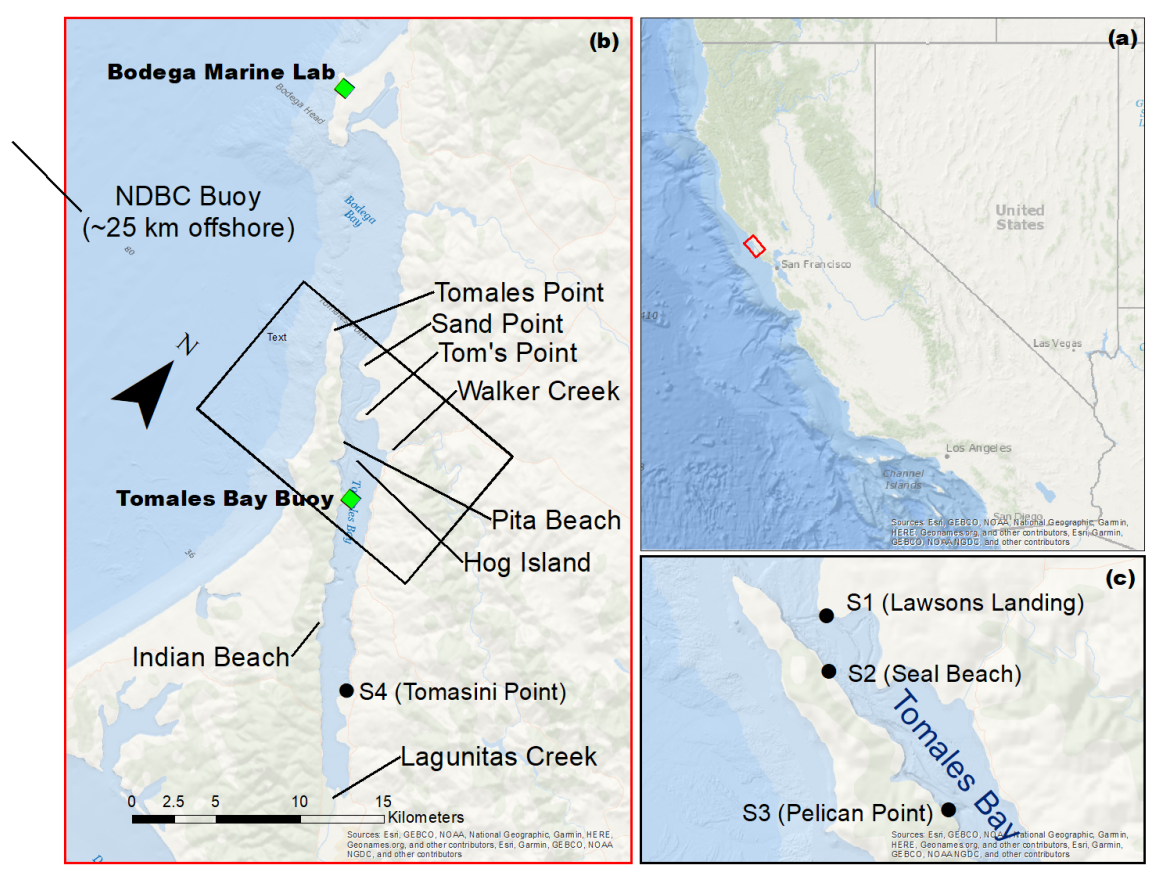

Figure 1. Locations of instruments (S1-S4) installed in Tomales Bay (b, c) as well as some geographic reference points. Only the outer bay is visible in (c). Context in California given in (a).

Table 1. Distance from the mouth was measured along the main axis of the bay from Tomales Point (Fig. 1). Distances between a sensor and its respective beach measured perpendicular to the beach front, to the upper beach.

\begin{tabular}{|c|c|c|c|}
\hline Sensor Name & Dist. from Mouth & Dist. from Beach & Elev. Above Bed \\
\hline Lawsons Landing (S1) & $2.2 \mathrm{~km}$ & $43 \mathrm{~m}$ & $460 \mathrm{~cm}$ \\
Seal Beach (S2) & $3.4 \mathrm{~km}$ & $28 \mathrm{~m}$ & $14 \mathrm{~cm}$ \\
Pelican Point (S3) & $7.7 \mathrm{~km}$ & $22 \mathrm{~m}$ & $20 \mathrm{~cm}$ \\
Tomasini Point (S4) & $17 \mathrm{~km}$ & $104 \mathrm{~m}$ & $5 \mathrm{~cm}$ \\
\hline
\end{tabular}

covered on 24 November 2019. S1 was zip-tied to the southwestern-most piling on the Lawsons Landing Pier, whereas the other three were zip-tied to screw anchors installed in the bay floor. More data on sensor locations are in Table 1.

\subsection{Weather and Buoy data}

The Bodega Marine Lab (BML) maintains the Bodega Ocean Observing Node (BOON), a suite of observing sensors at BML, in addition to various buoys. For our analysis, we used (non-gust) wind speed and direction data collected at BOON on land at Bodega Marine Lab, as well as by the Tomales Bay Buoy (TBB), anchored near Pelican Point inside Tomales Bay (Fig. 1). We also used wave data from Buoy 46013 (before it went adrift in 2021), managed by the National Data Buoy Center (NDBC), directed by the National Oceanic and Atmospheric Administration (NOAA) (NDBC, 2020). We used significant wave height $\left(H_{S}\right)$, dominant wave period $\left(T_{p}\right)$ and dominant wave direction data from Buoy 46013, offshore of Bodega Head, approximately $25 \mathrm{~km}$ northwest of the mouth of Tomales Bay. All data were logged hourly, with details included in Table 2.

Wind speed data were collected from the TBB, but direction data were compromised (Marcel Losekoot, personal communication). Therefore we compared wind direction data measured 
Table 2. Sources for data related to winds and offshore waves near Tomales Bay.

\begin{tabular}{|c|c|c|c|}
\hline Parameter & Collection Agency & Location & Regularity \\
\hline Wind Speed (non-gust) & BML & Tomales Bay Buoy & On The Hour \\
Wind Direction & BML & Bodega Head & On The Hour \\
Barometric Pressure & BML & Bodega Head & On The Hour \\
Water Salinity & BML & Tomales Bay Buoy & On The Hour \\
Water Temperature & BML & Tomales Bay Buoy & On The Hour \\
Offshore $H_{S}$ & NOAA & NDBC Buoy 46013 & Hourly at :40 \\
Offshore $T_{p}$ & NOAA & NDBC Buoy 46013 & Hourly at :40 \\
Offshore Wave Direction & NOAA & NDBC Buoy 46013 & Hourly at :40 \\
\hline
\end{tabular}

on Bodega Head by BML and Weatherunderground meteorological stations at Hog Island Oyster Company and Tomales Bay Oyster Company, who maintain stations between S3 and S4. Wind direction data were consistent across all three sites but the BML data had the fewest gaps, so we used wind direction data from BML and wind speeds from the TBB. However, the TBB had a gap in wind speed data between October 29th and November 16th 2019 thus we avoid this period in our analysis.

\subsection{Data Processing and Calculations}

Raw pressure data from the sensors, $p_{r}(t)$, were converted to water depth, $h(t)$, by subtracting barometric pressure, $p_{b}(t)$, from the nearest hour. These values were converted to hydrostatic depth $h(t)$ using 1 (where $z_{I}$ is the instrument height above bed and $g$ is gravitational acceleration).

$$
h(t)=\frac{p_{r}(t)-p_{b}(t)}{\rho(t) g}+z_{I}
$$

Water density values, $\rho(t)$, were calculated following Millero et al. (1980) which made use of the water temperature and salinity data from the nearest hour.

At each hour, a centered three-hour window of the water depth time series was broken into 45minute non-overlapping "instances" which were then de-trended. These 45 minute windows were long enough to capture representative averages of infragravity-band energies, but short enough so that depth timeseries were approximately linear. The Fast Fourier Transform was applied to each instance, yielding a power density spectrum of the depth signal $S_{d}(f)$, with frequency ranging from the inverse instance length to the Nyquist frequency.

The pressure sensors were bottom-mounted and thus have varying depths below the water surface based on tidal stage. The sensors' ability to detect pressure changes due to surface heights varies with depth below surface. Thus, we transformed each instance's depth spectrum into a surface height spectrum spectra $S_{\eta}(f)$ via

$$
S_{\eta}(f)=\left[\frac{N(f)}{K_{p}(f)}\right]^{2} S_{d}(f)
$$

where $\mathrm{N}$ is an empirical correction factor that we set equal to 1 (per Bishop and Donelan (1987), Equation 8), and $K_{p}(f)$ is the pressure response factor. This method is supported by Ellis et al. (2006) who used it to adjust wave spectra from boat wakes. For each instance, the mean water depth was calculated and used alongside the sensor height above the bed to complete the calculations. Following these corrections, we took the arithmetic mean of the four instances' spectra to represent the water surface energy density spectrum of each window. The spectral curves presented throughout the paper are the variance-preserving spectra so as to more easily visualize the frequency ranges that drive the most variation. Each ensemble was classified as either "Low Tide," "High Tide," "Flooding," or "Ebbing," based on the slope of and proximity of peaks and troughs in the depth signal over the ensemble. Categories were balanced to roughly equate the counts in 
141

42

143

144

each category over the entire study period. Differences described in Section 3.3 were the averages for each category across the entire study period.

At high water levels, small waves may not have penetrated deeply enough to be measured by the sensor. Therefore in order to avoid making calculations based off sensor noise in these scenarios, we used a high-frequency cutoff of

$$
f=\sqrt{\frac{g}{4 \pi\left(h-H_{S}\right)}}
$$

following Foster-Martinez et al. (2018), as the upper limit of frequency that penetrates to the depth of the sensor, based on linear wave theory. As a rough estimate of the worst case (deepest sensor, S1), motions on the order of $0.625 \mathrm{~Hz}(1.6 \mathrm{~s})$ may not be well-captured at high tides.

Our significant wave height values $H_{S}$ are $H_{m_{0}}$ values, found via

$$
H_{S}=4 \sqrt{m_{0}}
$$

145 where $m_{0}$ is the 0th spectral moment. To break $H_{S}$ into sub-components by wave type, we ${ }_{146}$ integrated within specified frequency bands that are detailed in Section 2.4, similar to Hughes et al. 147 (2014).

148 We compared our calculated $H_{S}$ values to those predicted by Equations 3-28a, 3-33, 3-34, 3-36 149 and 3-37 in the Shore Protection Manual (1984), which apply in deep-water fetch-limited and fully150 developed wave heights and periods for a given fetch and sustained wind speed, replicated here as 151 Equations 5 and 6. In these formulas, $U_{A}$ is an adjusted wind speed $\left(U_{A}=0.71 U^{1.23}\right)$ in $\mathrm{m} / \mathrm{s}$, where $152 U$, the wind speed, is also in $\mathrm{m} / \mathrm{s}$; $g$ is gravitational acceleration, and $F$ is fetch length in meters.

$$
\begin{aligned}
& \frac{g H_{S}}{U_{A}^{2}}=1.6 * 10^{-3}\left(\frac{g F}{U_{A}^{2}}\right)^{1 / 2} \\
& \frac{g T_{m}}{U_{A}}=2.857 * 10^{-1}\left(\frac{g F}{U_{A}^{2}}\right)^{1 / 3}
\end{aligned}
$$

153

154

162

156

161

When investigating loss of wave height due to frictional dissipation, we considered the exponential decay form used by Foster-Martinez et al. (2018), developed for marsh-edge but also applied to mudflats:

$$
\frac{H_{S}}{H_{S, \text { ref }}}=e^{-k_{i} x}
$$

where $H_{S, \text { ref }}$ is a reference wave height before dissipation, $k_{i}$ is a frictional dissipation rate (in $1 / \mathrm{m})$, and $x$ is meters of distance traveled by a wave.

Using the dispersion relationship $f^{2}=g k \tanh (k h)$, we found the wavenumbers $(k)$ for a given frequency $(f)$ which were used to calculate phase and group speeds $\left(C_{p}\right.$ and $C_{g}$ respectively) of waves in water depth $h$.

$$
C_{p}=\operatorname{sqrt}\left(\frac{g}{k} \tanh (k h)\right)
$$

$$
C_{g}=C_{p} *\left(\frac{1}{2}+\frac{k h}{\sinh (2 k h)}\right)
$$

The wave power on a per-frequency basis was calculated as

$$
\bar{P}(f)=\bar{\epsilon}(f) * C_{g}(f)
$$

163 We calculated bottom velocities and shear stresses, $u_{b}$ and $\tau_{b}$ respectively, following Wiberg and ${ }_{164}$ Sherwood (2008) for consideration of onset of sediment motion where $h$ is water depth $(\mathrm{m})$ and $k$ 165 is the wavenumber $(1 / \mathrm{m})$.

$$
u_{b}=\frac{H_{S} \pi}{T \sinh k h}
$$




$$
\tau_{b}=\frac{\rho f_{w}}{2} u_{b}^{2}
$$

We used $f_{w}=2 R e_{w}^{-0.5}$ as the wave friction factor (per Nielsen (1992)) which assumes a laminar wave boundary layer, as all measurements (except for $2 \%$ of those at S4) met the $R e_{w}<3 * 10^{5}$ criterion.

We then calculated the Shields Parameter $\tau_{*}$ using Equation 13 to evaluate the onset of granular motion under the waves per Madsen and Grant (1975).

$$
\tau_{*}=\frac{\tau_{b}}{\left(\rho_{s}-\rho\right) g D_{50}}
$$

Where $\rho_{s}$ is the sediment density, $\rho$ is water density, and $D_{50}$ is the median grain size.

\subsection{Frequency Band Classification}

We established cutoffs in frequency to delineate wave types to separate waves generated inside the bay by local winds (which may include some high-frequency wind waves generated offshore, although expected to dissipate as they travel through shoals and strong currents at the mouth) from remotely generated swell waves and regionally generated low-frequency wind waves that propagate into the Bay. In the following we will use swell waves to refer to both true ocean swell as well as low-frequency wind waves generated by strong and spatially extensive regional winds along the coast of California. Infragravity oscillations may be generated offshore or as swell waves shoal by various mechanisms ("infragravity waves" or "IGW"), as discussed in Bertin et al. (2018).

Assuming that waves generated by local winds in Tomales Bay are fetch-limited, we used Equation 6 to suggest a maximum possible wave period for waves generated by N/NW winds. We used $1.1 \mathrm{~km}$ as the fetch between the mouth of Tomales Bay and S2, and $10.2 \mathrm{~km}$ as the fetch between Hog Island (see Fig. 1) and S4, an expanse free of major shoals and points. A sustained maximum wind speed of $6 \mathrm{~m} / \mathrm{s}$ led to a calculated $2.5 \mathrm{~s}$ as maximum generated period for wind waves. However, with peak sustained winds of $6 \mathrm{~m} / \mathrm{s}$ during our deployment, we saw high wave energy at frequencies as low as $0.25 \mathrm{~Hz}(4 \mathrm{~s})$ at $\mathrm{S} 4$. As the fetch may be slightly larger if we consider the fetch from Tom's Point (Fig. 1), and wind speeds occasionally higher, a 4s cutoff would classify most of the waves generated inside the bay as locally-generated wind waves. Equation 5 suggested a maximum wave height of $33 \mathrm{~cm}$ generated by fetch-limited conditions at $\mathrm{S} 4$. We did not record $H_{S}$ values this large at $\mathrm{S4}$, and address this discrepancy in Section 4.1.

Waves with frequencies lower than $0.25 \mathrm{~Hz}(4 \mathrm{~s})$ but higher than $0.04 \mathrm{~Hz}(25 \mathrm{~s})$ are classified as swell. The cutoff separating swell from infragravity is based on Okihiro and Guza (1995) and Bertin et al. (2018). The maximum dominant wave period measured during our study period at NDBC Buoy 46013 was $21.5 \mathrm{~s}(0.0465 \mathrm{~Hz})$, within our cutoff. We applied the long-period limit of IGW motions at $300 \mathrm{~s}(0.003 \mathrm{~Hz})$ due to its agreement with Okihiro and Guza (1995), Williams and Stacey (2016), and Beach and Sternberg (1992).

\subsection{Sediment Grain Size}

Surface sediment samples ( $3 \mathrm{~cm}$ deep) were collected by hand during initial sensor installation in June 2019 at the beaches near S1, S2, and S3, with three samples per site chosen at random from the upper beach. The samples were dried in an oven at $90^{\circ} \mathrm{F}$ overnight and then sieved using Hogentogler meshes selected to focus on fine-to-coarse sand to develop grain size distributions by mass. Mesh sizes used were 16, 11.2, 8, 5.6, 4, 2.8, 2, 1.4, 1, 0.71, 0.5, 0.355, 0.25, 0.18, 0.125, 0.09 , and $0.063 \mathrm{~mm}$, which are approximately evenly-spaced increments in phi space (Wentworth, 1922). Values presented are the mean of the three D50 values (from the three samples). There were no sediment samples taken at the beach at S4. 


\section{Results}

\subsection{Overview of Observed Wave Field}

The most common wave direction at the offshore buoy was $313^{\circ}$, aligned with the regional shoreline (Fig. 1), and the distribution of directions was almost exclusively between 295 and $320^{\circ}$, only deviating significantly during conditions with small waves. Also visible in Fig.2d, wave height $H_{S}$ at the offshore buoy stayed above $1 \mathrm{~m}$ and dominant wave period $T_{p}$ was nearly always above $8 \mathrm{~s}$. Modal wave conditions were punctuated by low-frequency swell events with $H_{S}>2 \mathrm{~m}$. The buoy recorded a maximum $H_{S}$ of $4.73 \mathrm{~m}$ and maximum period $T_{p}$ of $19 \mathrm{~s}$ during our study period. As expected for waves generated remotely, $T_{p}$ at the buoy decreased during these swell events. During swell events with wave heights $>2.5 \mathrm{~m}$ and dominant wave periods $>12 \mathrm{~s}$ at the buoy, there was a concurrent increase in wave energy across a broad range of lower frequencies (i.e. infragravity waves) at the sensors. In addition to swell events, high-frequency wave events occurred during wind events (i.e., regionally generated wind waves) with wave heights of $2 \mathrm{~m}$ and wave period $<8$ $\mathrm{s}$. Together these swell waves and regional wind waves comprise the ocean waves incident on the mouth of Tomales Bay.

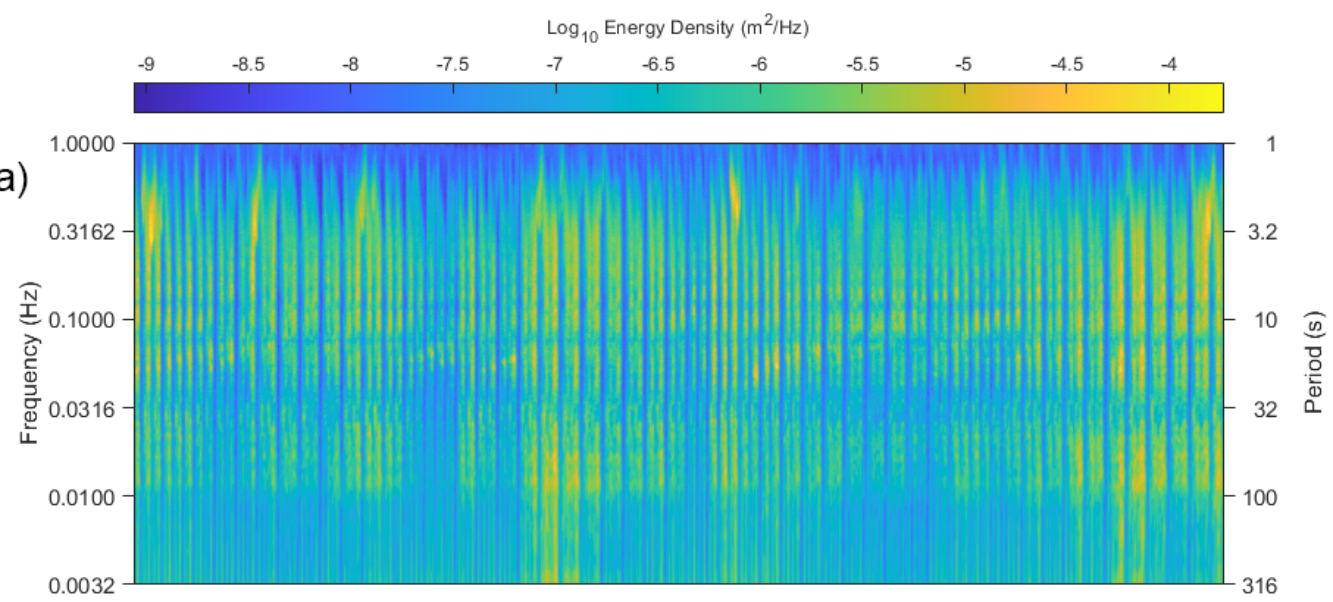

(b)

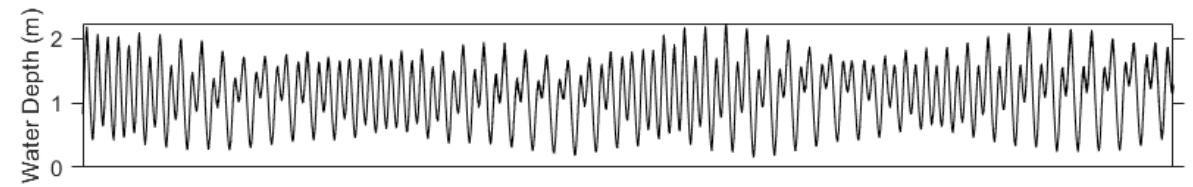

(c)

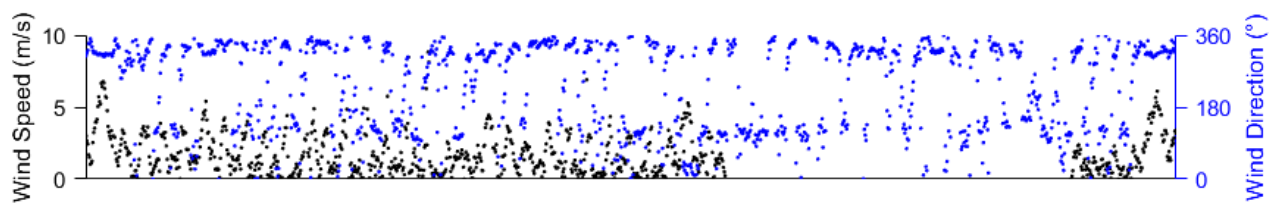

(d)

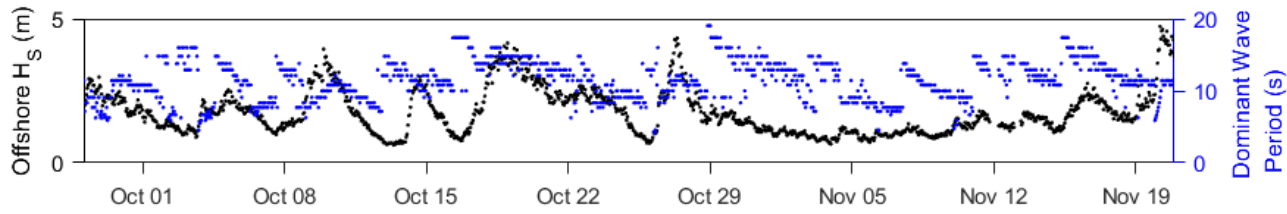

Figure 2. Wave energy density spectra at S2 (a), water depth at S2 (b), in-bay wind conditions (c), and offshore wave conditions (d) plotted over time during our study period in 2019. 
When winds in Tomales Bay exceed $5 \mathrm{~m} / \mathrm{s}$ they also occur regionally, resulting in high-frequency local wind waves in the bay concurrent with low-frequency regional wind waves generated outside the Bay (Fig.2C). Between these synoptic wind events a daily sea-breeze pattern was observed with calm mornings (wind speed $<2 \mathrm{~m} / \mathrm{s}$ ) followed by higher winds in the late afternoon and evening (speeds typically 3-4 m/s). Winds were mostly northerlies orientated with the longitudinal axis of the Bay (Fig. 1), with directions between 270 and $360^{\circ} \mathrm{N}$ and centered on 310. At times weaker southerly winds were observed, also oriented along the Bay (direction $\left.120^{\circ} \mathrm{N}\right)$. Weak winds $(<2$ $\mathrm{m} / \mathrm{s}$ ) did not always align with the Bay.

The time-averaged spectral power level was less than $1 * 10^{-5} \mathrm{~m}^{2} / \mathrm{Hz}$ at all four sites over our study period. From Fig. 2a, it is evident that waves were modulated by tides and punctuated by occasional events when spectral power levels exceeded $1 * 10^{-4.5} \mathrm{~m}^{2} / \mathrm{Hz}$ at peak frequencies (henceforth referred to as "high-energy events"). These events are driven by particular combinations of tide, wind, and swell conditions, outlined below and discussed in Sections 4.1 and 3.2.

Spectra from S1 (Lawsons Landing, closest to the mouth) displayed very low high-frequency energy, likely due to the sensor being deployed on a south-facing beach, protected from ocean waves and not exposed to locally generated waves during northerly winds. However, low-frequency ocean waves can refract around Sand Point (see Fig. 1) and were observed at this sensor. Lowfrequency energies at $\mathrm{S1}$ were higher and behave differently than those at any other sites within the Bay. In this paper we focus on data from S2 (Seal Beach) as more representative of ocean-waveinfluenced beaches near the mouth of Tomales Bay. Waves at S3 (Pelican Point) exhibited similar wind-related patterns as S4 (Tomasini Point), but with lower energy due to shorter fetch. Thus, to represent wind-dominated beaches further landward in the Bay, we focus on data from S4.

The ocean-wave-influenced site at S2 in outer Tomales Bay was regularly exposed to waves with frequencies less than $0.25 \mathrm{~Hz}$ and the spectra exhibited broad peaks centered around 0.017 $\mathrm{Hz}, 0.06 \mathrm{~Hz}, 0.1 \mathrm{~Hz}$, and $0.15 \mathrm{~Hz}$, with no peak at higher frequencies (Fig. $3 \mathrm{~d}$ ). In contrast, the windwave-influenced site at $\mathrm{S} 4$ exhibited a unimodal spectral curve, with spectral peak between 0.3 and $0.6 \mathrm{~Hz}$ (centered at $0.4 \mathrm{~Hz}$ ). This spectral peak was an order-of-magnitude higher than that observed at S3 or S2.

\subsection{Temporal Variability in Wave Spectra}

The modal wave conditions described above were punctuated by high-energy events from swell arriving at the mouth or by wind events that generated both regional wind waves outside the mouth and local wind waves inside the Bay. Here we compare wave spectra for calm conditions (October 12; Fig. 3a), windy conditions ( $>5 \mathrm{~m} / \mathrm{s}$, September 28-29; Fig. 3b), and big-swell conditions $\left(H_{S}>2\right.$ $\mathrm{m}$ at offshore buoy, November 15-16; Fig. 3c). On days with both high winds and big swell, wave spectra were linear combinations of those from windy and big-swell days. During calm conditions (October 12), wave energy was low across all frequencies at both S2 and S4 (Fig. 3a), with a weak swell peak at S2 centered at $0.064 \mathrm{~Hz}$ and a weak wind-wave peak at S4 centered at $0.55 \mathrm{~Hz}$.

\section{The Wave Field during Wind Events}

The prevailing northerly winds in Tomales Bay had marked diurnally variability (Fig. 2 and Fig. 4), accounting for higher-than-background wind-wave $H_{S \text {,wind }}$ values (Fig 4) in the late afternoon and evening (Fig. 4a). These diurnal patterns were more prominent at sites further inside the bay (e.g. S3 and particularly S4). The wind-wave spectral peak is evident at all sites and most pronounced at site S4 (Fig. 3b), which is exposed to the longest fetch for northerly winds. On September 28, winds $>5 \mathrm{~m} / \mathrm{s}$ were sustained all day. The spectral peak at S2 was centered around $0.45 \mathrm{~Hz}$ with peak energy of $3 * 10^{-5} \mathrm{~m}^{2} / \mathrm{Hz}$ whereas at $\mathrm{S} 4$ the peak was centered at $0.33 \mathrm{~Hz}$ and peak energy is $55 * 10^{-5} \mathrm{~m}^{2} / \mathrm{Hz}$.

Wave spectra during other wind events exhibited similar spectral peaks (e.g., October 4 and November 19). However, the wind-wave field also developed almost every afternoon, most pronounced at S4 but also at S3 and S2 when winds were stronger, (Fig. 4). Note that peaks in $H_{S \text {, wind }}$ 

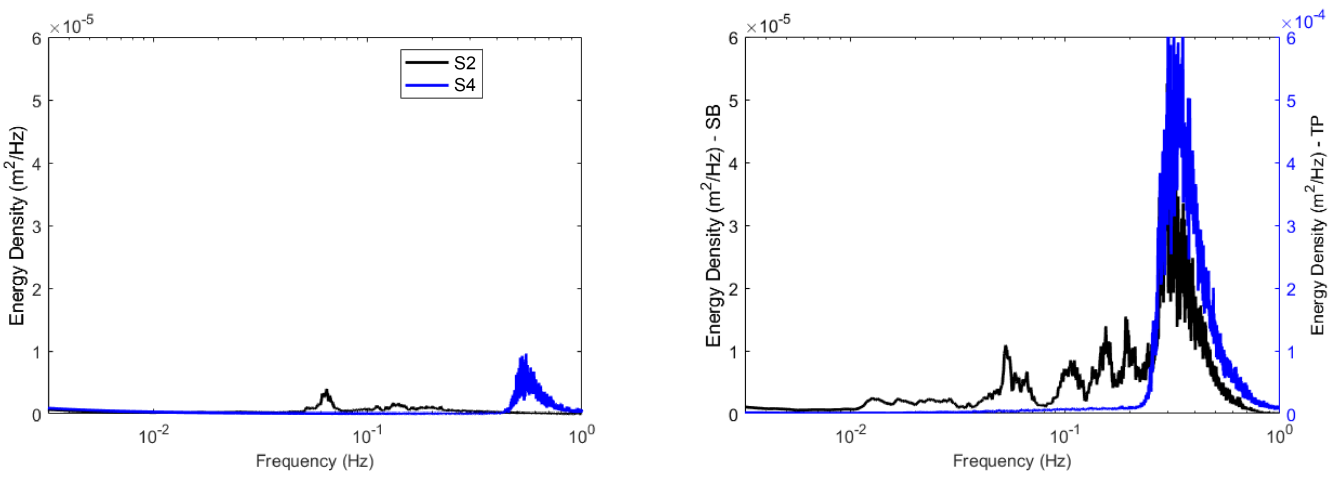

(a)

(b)

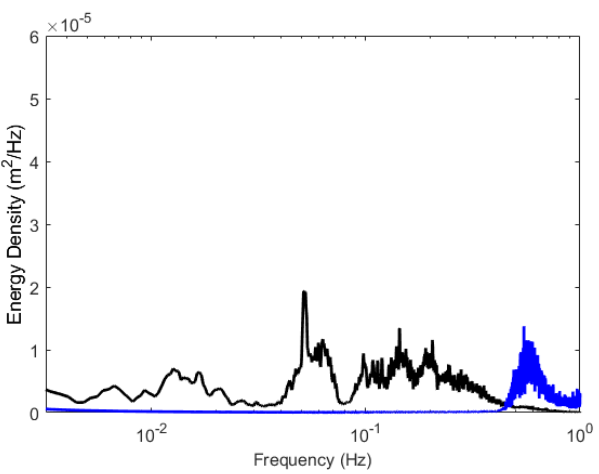

(c)

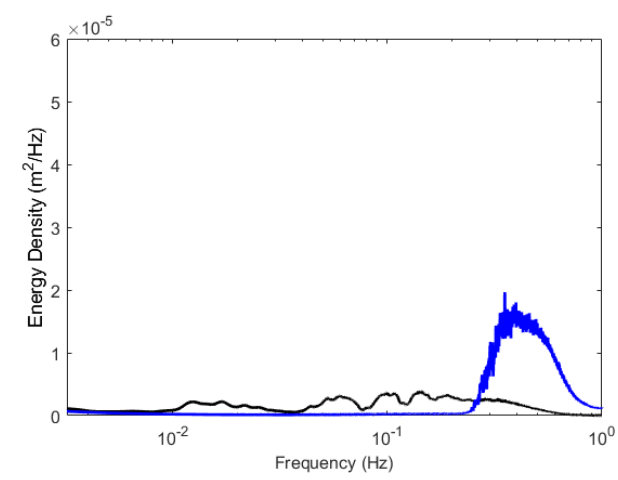

(d)

Figure 3. Spectra from S2 and S4 on calm (a), windy (b) (note different axis scale for S4), and high-swell (c) days, as well as the study average (d). 
were not always exactly concurrent with peak wind stress. Peaks in $H_{S \text {, wind }}$ were also observed at $\mathrm{S} 1$, but with shifting phase relative to diurnal peaks in winds and waves at other sites. Wind wave peak heights coincided with stronger falling tides, occurring diurnally during spring tides and semidiurnally during neap tides, demonstrating that ebb tide currents alter the propagation of wind waves in the outer Bay.

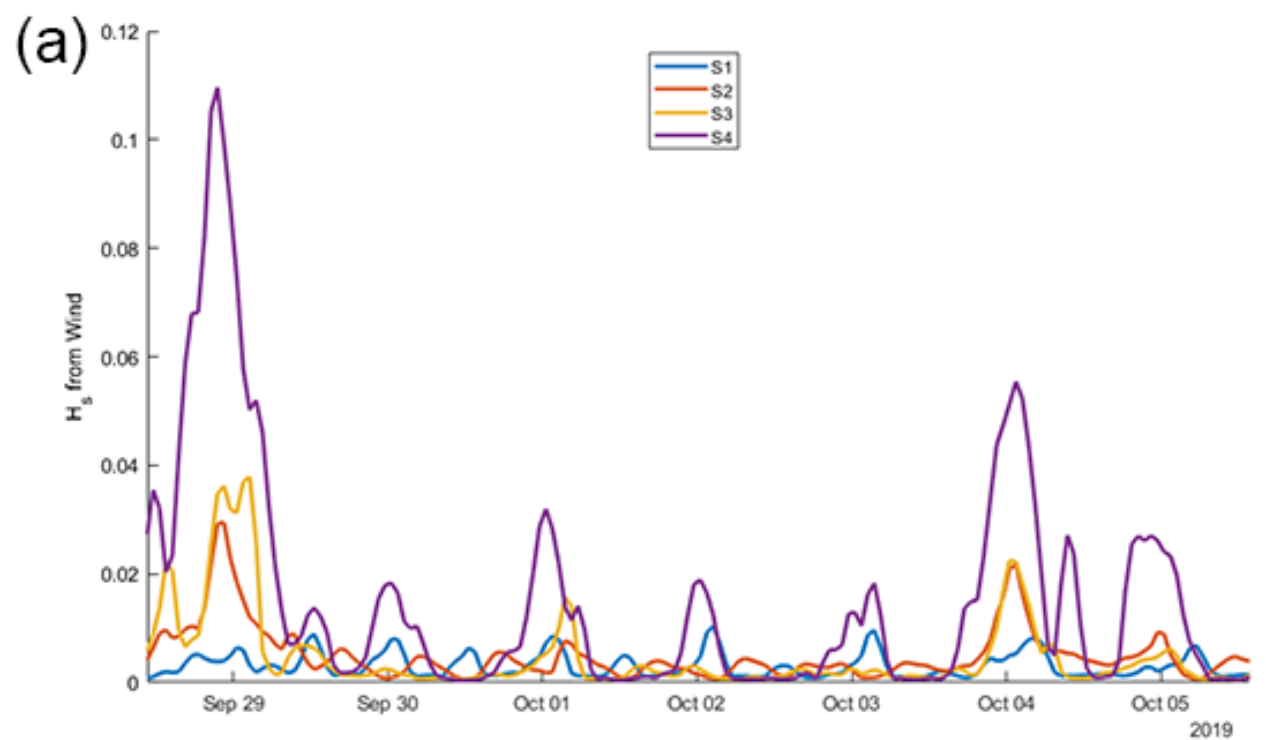

(b)

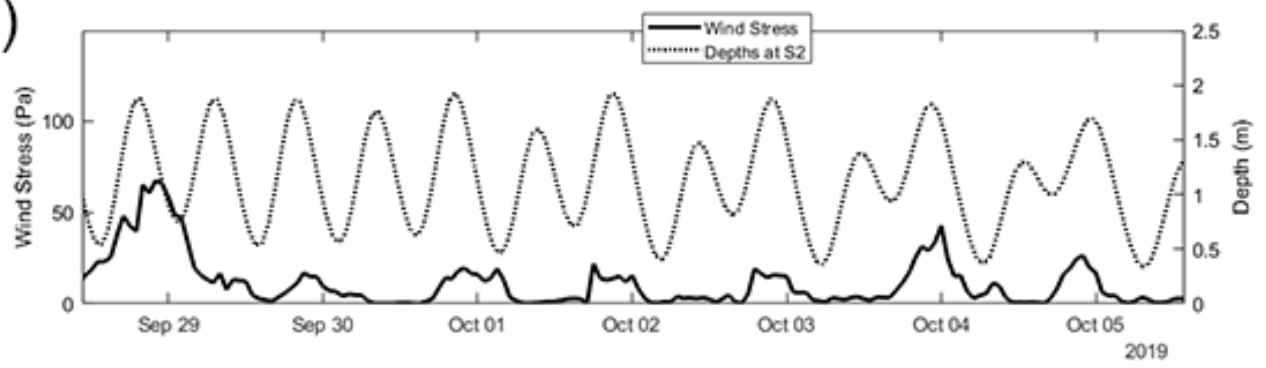

Figure 4. Peaks in wind wave height are evident in the $H_{S \text {,wind }}$ timeseries over a sample of our study period at all four sensor locations. High wind waves ("wind events") were generally synchronized across the sensor sites with the exception of S1, which may only have sensed small wind waves at low tides.

The Wave Field during Swell Events

During our study period, monthly average significant wave height at the offshore buoy was 1.8$2.5 \mathrm{~m}$ and average wave period was 10.4-12.3 s (0.081-0.096 Hz) (NDBC, 2020). On November 15 the wind was weak, but significant swell was recorded at the offshore buoy (wave height $2.5 \mathrm{~m}$, period $15 \mathrm{~s}$ ), resulting in low-frequency spectral peaks at S2, centered at $0.0615 \mathrm{~Hz}, 0.0993 \mathrm{~Hz}$, and $0.1434 \mathrm{~Hz}$ (Fig. 3c) and the absence of any wind-wave energy. At site S4, beyond the reach of ocean waves, a weak wind-wave peak was observed and the wave field was similar to that of a calm day (Fig. 3a). The spectral peaks at S2 represent swell and infra-gravity-wave periods, which are remarkably consistent over time (Fig. 2) and evident also in the average spectrum at S2 (Fig. 3d).

Throughout our study period, swell and infra-gravity energy were observed at S1 and S2 (2.2 and $3.4 \mathrm{~km}$ from Tomales Point, respectively) but not at S3 or S4. Further, no swell or infra-gravity- 

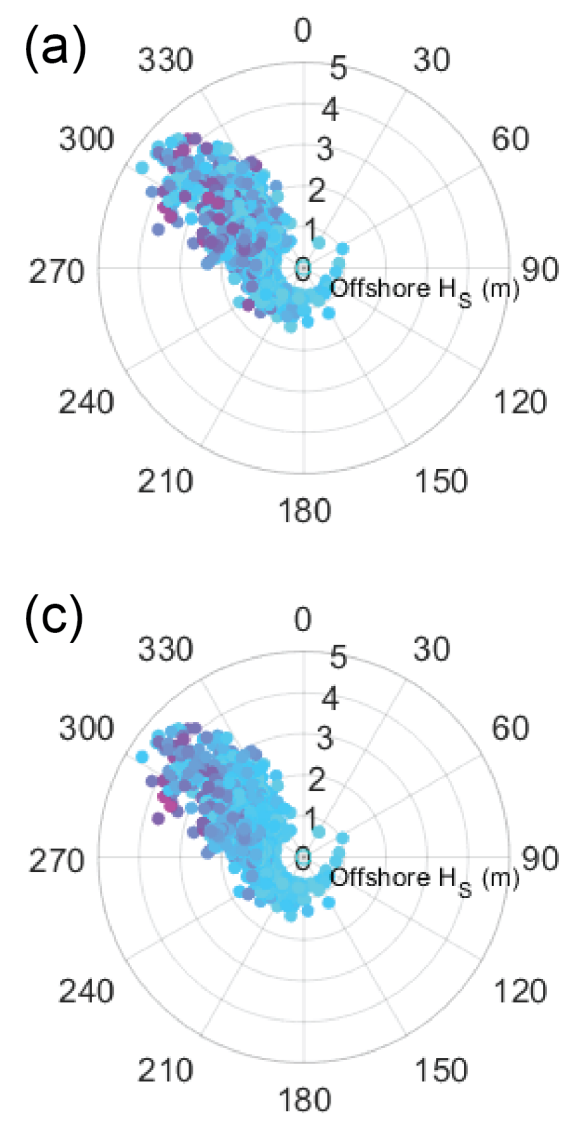
at the offshore buoy. 3.3, 4.2, and 4.3.
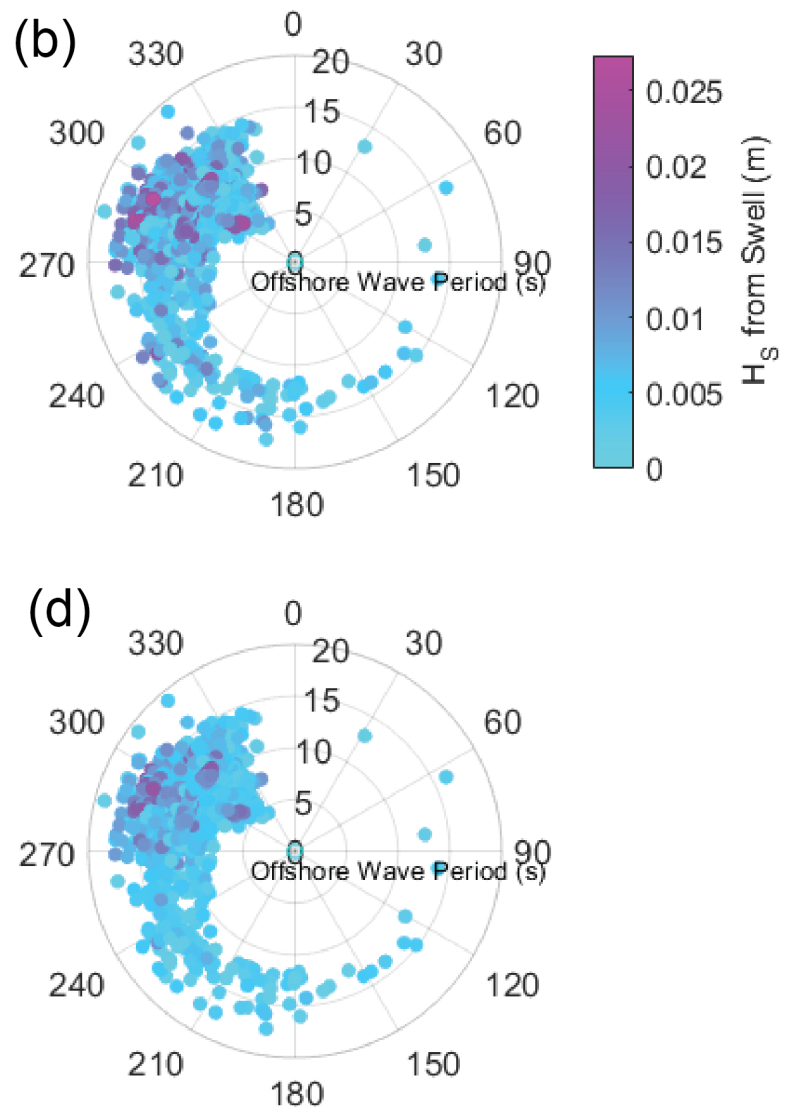

Figure 5. Each 45 min window in our study period is plotted as a point. Swell wave-(a) and (b)-and IGW-(c) and (d)-wave heights at S2 were dependent on offshore wave height and period. Additionally, large offshore waves and large $H_{S, I G W}$ and $H_{S \text {,swell }}$ values only arise from the northwest, which is also the orientation of Tomales Bay.

wave energy was recorded by a sensor deployed between S2 and S3 during summer (Wall Beach, (S1 and S2) and coincided with large waves at the offshore buoy (Fig 5 and Fig. 6). Swell and infragravity waves at $\mathrm{S} 2$ were small $\left(H_{S}<2.5 \mathrm{~cm}\right)$, but strongest when offshore ocean waves exhibited dominant direction from $285-315^{\circ} \mathrm{N}, H_{S \text {,buoy }}$ between 3-4 $\mathrm{m}$, and $13.5-16 \mathrm{~s}$ as the dominant period (Fig. 5). During our study period, $4 \mathrm{~m}$ and $16 \mathrm{~s}$ were the largest and longest-period waves recorded

Swell energy varies on diurnal/tidal time scales (Fig. 6a), but variability is different at S2 and S1. At S1, swell wave peaks align with larger falling tides (as do wind wave peaks), resulting in diurnal peaks during spring tides and twice-a-day peaks during neap tides. In contrast, S2 swell wave peaks align with high tide phase (high water levels). These tidal controls are further explored in Sections

\subsection{Tidal Modulation of Wave Field}
In addition to fluctuations in wave sources, waves at beaches in Tomales Bay varied significantly with the tides, due to the effect of changes in water depth and currents associated with tides. Spectra calculated across different tidal conditions show highest ocean wave energy at S2 during high tides, and lowest energy during ebb and low tides (Fig. 7). However, the highest frequency, local wind waves at both S2 and S4 show most energy during ebb tides-while lower energy at high 
(a)

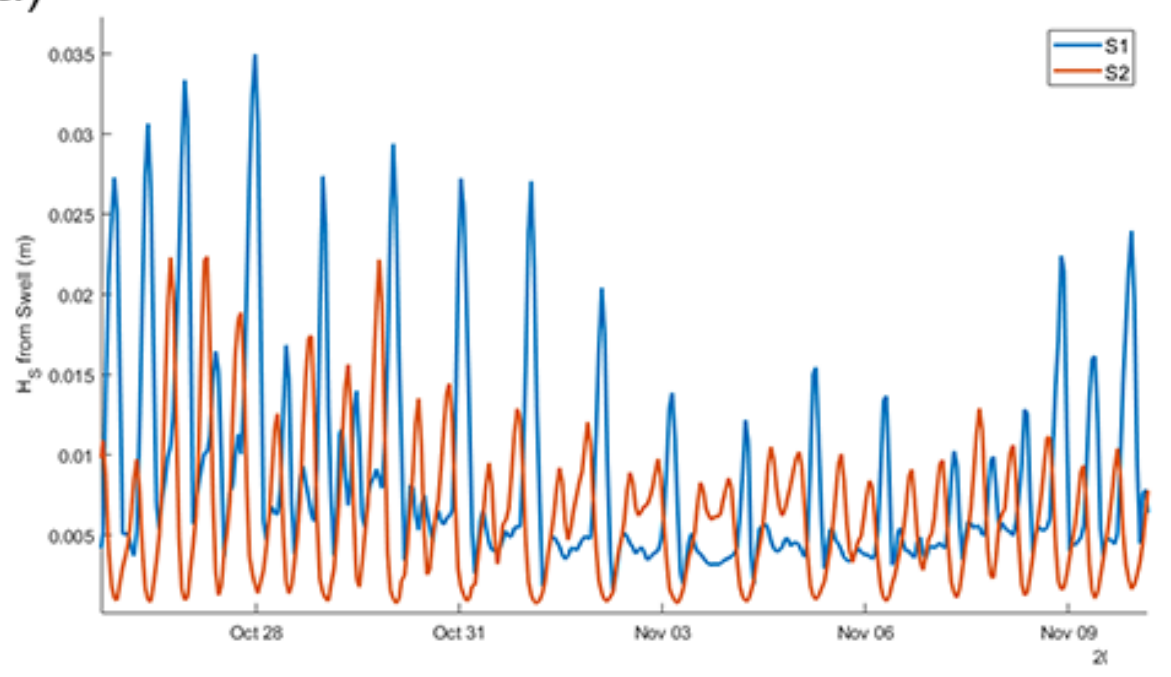

(b)

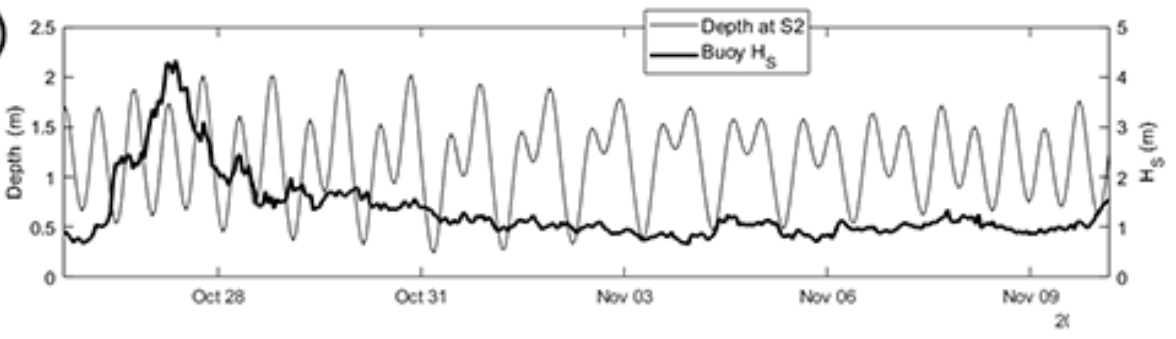

Figure 6. $H_{S \text {,swell }}$ at S1 and S2 over some select days (a), along with corresponding water depths and wave heights at the NDBC Buoy (b). The significant wave heights at S1 and S2 follow the arriving swell, with strong modulation by tidal conditions.

tides may be explained by the depth of the sensor (an imperfect correction is given by Equation 2), ebb-tide energy is notably greater than flood-tide energy (same water depth). This is most striking at $\mathrm{S} 4$ for wave frequencies $>0.3 \mathrm{~Hz}$ (Fig. 7b).

During low-slack and flooding conditions, the peak of S4's spectrum reduced in magnitude and width, and its center moved upwards in frequency to near $0.5 \mathrm{~Hz}$. At high-slack, the spectrum more skewed towards lower frequencies than other conditions, with a center at $0.34 \mathrm{~Hz}$. Note also that for S4 at high-slack, frequencies higher than $0.785 \mathrm{~Hz}$ have near-zero variances. This is the cut-off frequency (Equation 3) at a depth of $1.3 \mathrm{~m}$. The sensor was under this much water for $52 \%$ of the high tide bins, so we attribute this drop in energy to the sensor's inability to pick up high-frequency waves at high tide. This may mean our $H_{S, \text { wind }}$ values at $\mathrm{S} 1$ are artificially low. However, if we assume that the energy values above $0.785 \mathrm{~Hz}$ are comparable to their average across other tidal conditions, they would only contribute only $<2 \%$ to the total energy in the wind band, both during normal and windy conditions.

\subsection{Sediment Size \& Sediment Entrainment by Waves}

The average $D_{50}$ of the three beaches were $0.21,0.29$, and $0.63 \mathrm{~mm}$ with $D_{84}-D_{16}$ spread values of $0.10,0.24$, and 2.5 at S1, S2, and S3, respectively. Distributions at these four sites were unimodal with peaks in the sand range $(0.062-2 \mathrm{~mm})$. Sediment that passed through the smallest $0.063 \mathrm{~mm}$ mesh was considered "fine" and did not contribute more than $0.01 \%$ of the total sample weight in any sample. Some distributions were pure sand while the $\mathrm{S} 3$ samples had tails in the grain size distribution with fine-to-coarse pebble contributions (reflected by the larger spread metric). Although 

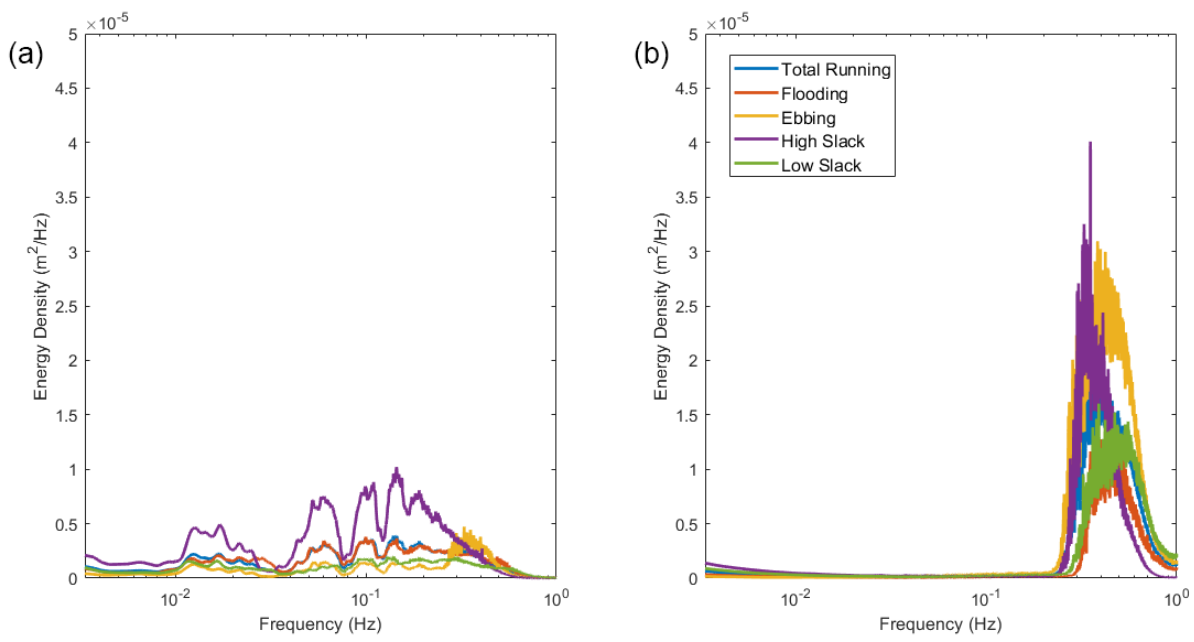

Figure 7. Tidal stage and currents affect the shape of the average spectral curves in different ways at S2 (a) and S4 (b).

no sediment was collected at the beach corresponding to S4, on field visits it was observed to be highly mixed with mud, sand, and pebble-size grains.

We considered grain entrainment as an indicator of beach-building potential. The $\tau_{b}$ values via Equation 12 at S4 reached peaks of $0.18 \mathrm{~Pa}$, typically at times with lower water levels $(<0.6$ $\mathrm{m}$ water depth at the sensor) and high winds (>4 m/s), where wind waves contributed over $70 \%$ of the total spectral energy. During calm-wind periods bed stress values were low with peaks of $\tau_{b} \approx 0.05 \mathrm{~Pa}$ that occurred only at very low water levels. Background conditions between peaks had $\tau_{b}$ values near $0.01 \mathrm{~Pa}$. These bed stress values of $0.18,0.05$, and $0.01 \mathrm{~Pa}$ would cross the critical $\operatorname{tau}_{*}$ (Equation 13) threshold of 0.047 for grain sizes of $0.24 \mathrm{~mm}, 0.067 \mathrm{~mm}$, and $0.013 \mathrm{~mm}$ respectively, all within a fine sand-silt range.

In contrast, $\tau_{b}$ values at S2 reached peak values of only $0.035 \mathrm{~Pa}$, lower than at $\mathrm{S} 4$, with peaks typically at higher water levels ( $>1.6 \mathrm{~m}$ at the sensor) when $H_{S}$ values at the offshore buoy were $>2$ $\mathrm{m}$. These bed stresses should initiate motion of an $0.047 \mathrm{~mm}$-diameter particle (coarse silt) at the sensor. Based on the $D_{50}=0.29 \mathrm{~mm}$ value from the beach behind S2, $\tau_{*}$ values (from Equation 13) never crossed the critical threshold of 0.047 during our study period, with $\tau_{*}$ peaking at values near 0.01 . On average, wind waves contributed $25 \%$ of the total spectral energy at $S 2$, and up to $42 \%$ on windy days (24-hour averages). There is clear differentiation in proportion of swell and infragravity wave energy contributions by depth: for high water levels ( $>1.6 \mathrm{~m}$ at sensor), swell contributed the most to the total spectral energy $(>60 \%)$; at low water levels $(<0.8 \mathrm{~m}$ at sensor), the same is true for infragravity waves.

\section{Discussion}

Spatial and temporal changes in the spectra of wave energy at beaches in Tomales Bay depend on the multiple processes, including wave generation, propagation, and dissipation. Wave sources are local wind-wave generation in the Bay and intrusion of ocean waves into the Bay. Dissipation en-route from source to beach is controlled by water depth and strong currents, both controlled by tides, and work done on the beaches depends on the dissipation of wave energy adjacent to or on the beach itself. We discuss these processes below.

\subsection{Generation of Local Wind Waves}

This study shows that, for mesotidal environments, tidal stage is an important control on the relationship between wind stress and wave heights. High wind speeds have the potential to de- 
velop large wind waves, and the largest waves at our sensors were recorded when high winds cooccurred with high water levels (Fig. 4). This finding agrees with the conceptual model explained in Pereira et al. (2020) and results by Trindade et al. (2016), who found that $H_{S}$ and wave period $T_{m}$ increased with water depth over macrotidal mudflats due to increased dissipation at low water levels. Thus, wave metrics near the beach vary on a tidal timescale if wind forcing is held constant. This effect cannot be explained purely by longer fetch at high water: using Equations 5 and 6 (from Coastal Engineering Research Center (1984)) and assuming a minimum beach slope of 0.03 within the intertidal zone, even an exaggerated tidal range of $2.5 \mathrm{~m}$ (close to a maximum spring tide) would drive a less-than $100 \mathrm{~m}$ lengthening of the fetch. Over the $10.2 \mathrm{~km}$ fetch between Hog Island and S4 (Fig. 1), the changes in predicted $H_{m 0}$ and $T_{m}$ are $<1 \%$. Over the $1.0 \mathrm{~km}$ fetch between Hog Island and S3, both $H_{m 0}$ and $T_{m}$ would change by $<8 \%$. As such, the stronger control mechanisms on wave development are likely bottom dissipation or wave amplification by opposing currents (Davidson et al., 2008).

It appears that fetch-limited wind waves in Tomales Bay dissipate much of their energy over shoals and low-tide terraces before they reach beaches. Wave heights predicted using equations from the Shore Protection Manual (Coastal Engineering Research Center, 1984) in Section 2.4 (i.e. $0.33 \mathrm{~m}$ at S4) were much higher than those calculated from our data; we observed maximum $H_{S, \text { wind }}$ values at S4 of $0.11 \mathrm{~m}$ (at high tide) and $0.06 \mathrm{~m}$ (at low tide) during hours of $>5 \mathrm{~m} / \mathrm{s}$ winds centered around 22:00 on September 28th. By assuming that the predicted wave heights were generated, we can quantify exponential decay in wave height over mudflats and seagrass meadows before reaching our sensor locations. Using the framework from Foster-Martinez et al. (2018) and Equation 7, with $x$ and $k_{i}$ as free parameters, and assuming that the decay constant is $\mathcal{O}\left(10^{-3}\right)$ (from Foster-Martinez et al. (2018)), our mudflat/shoal length must extend 100-1700 m from the sensor. Bathymetry from Tomales Bay by Anima et al. (2008) confirms that there is nearly $500 \mathrm{~m}$ of shallow ( $<1 \mathrm{~m}$ ) depth (MLLW) off of Tomasini Point, and at least another $500 \mathrm{~m}$ of $<2 \mathrm{~m}$ depths beyond that, confirming our order-of-magnitude comparison. At S4, observed waves remained well below the predicted fetch-limited wave height, but wave height versus wind speed data fit the curve predicted by Equation 5 if we account for $500 \mathrm{~m}$ of friction attenuation with a $k_{1}$ value of $4 * 10^{-3} \mathrm{~m}^{-1}$. An expanse of seagrass that fronts the mudflat may justify this higher $k_{1}$ value. Our observed energy density values of $0.39 \mathrm{~Hz}$ during high wind events at S2 and $\mathrm{S} 4\left(1.5 \mathrm{~cm}^{2} / \mathrm{Hz}\right.$ and $15 \mathrm{~cm}^{2} / \mathrm{Hz}$ respectively) are comparable to those in Collins (1972) for similar fetch lengths and $5 \mathrm{~m} / \mathrm{s}$ winds in shallow water. This implies that wave dissipation by bottom friction may lead to substantive discrepancies between observed wave heights and those predicted by Equation 5. .

\subsection{Intrusion of Ocean Waves}

Our findings show that swell and infragravity waves were fully attenuated beyond $3.4 \mathrm{~km}$ from Tomales Point, due to dissipation as they propagate over shoals and through narrow channels. Visual observations suggest that there is a marked decrease in ocean wave energy in the vicinity of Sand Point Fig. 1). Swell and infragravity energy observed in the outer Bay was partially controlled by the height and period of offshore waves observed at the offshore buoy (as in Fig. 5). Oceanic swell has been observed on mudflat-fronted shorelines in nearby San Francisco Bay and similarly correlated with offshore wave energy by Talke and Stacey (2003). Hughes et al. (2014) point to a linear relationship between energy levels from swell and IGW versus deep water wave height, but in our study there was only a rough relationship (Fig. 5). Instead, most of the variation in $H_{S \text {,swell }}$ appeared controlled by tidal patterns, i.e., $1 \mathrm{~m}$ "baseline" $H_{S}$ values at the offshore buoy were sufficient to account for swell effects at S2 (Fig. 6). Highest swell and infragravity wave energy was observed at S2 at high tide, in contrast to Okihiro and Guza (1995) who found that infragravity energy $(0.003-0.04 \mathrm{~Hz})$ was lowest at high tide across sites in the Southern California Bight. However, they suggest that this tidal modulation in energy at their 8-30m deep offshore sensors is controlled by tidal changes in beach face slope and reflection of infragravity waves. Due to the dissipative and low-slope nature of the coastline inside Tomales Bay, it is unlikely that reflection is 
important and the observed tidal fluctuations are explained by changes in dissipation. With water depths in Tomales Bay ranging from $<1 \mathrm{~m}$ in the shoal areas to $20 \mathrm{~m}$ in the narrow channel (Anima et al., 2008), infragravity waves are expected to experience attenuation due to bottom friction or by transferring their energy to higher frequencies, a mechanism suggested by Bertin et al. (2018). This attenuation is exacerbated during low tides as can be seen in the vertical banding in Fig. 2a. We can infer that the outer Bay beaches are influenced more by swell waves that arrive routinely at high tide, in contrast to inner Bay beaches that require an alignment of both high tides and local wind events to receive substantial wave energy.

\subsection{Tidal Effects on Waves}

Tidal currents are known to modify spectral distributions and wave energy (e.g. Huang et al. (1972), Dodet et al. (2013)), especially in bays where ebbing currents may "block" swell and infragravity waves from entering the inlet (Chen et al. (1998) and Bertin et al. (2018)). In our study, ebbing tidal currents amplified high-frequency spectral energies across the entire embayment. Tidal currents in Tomales Bay reach a maximum of about $1 \mathrm{~m} / \mathrm{s}$ in the channels of the outer bay (Gross and Stacey, 2004). During maximum ebb tide currents, waves with group celerity less than $1 \mathrm{~m} / \mathrm{s}$ may not be able to enter Tomales Bay - this celerity corresponds with waves with frequency above $0.78 \mathrm{~Hz}(1.28 \mathrm{~s})$ as solved using Equations 9 and 8 using $11 \mathrm{~m}$ as a reference depth of the mouth of Tomales Bay (Anima et al., 2008). This value is close to our Nyquist limit, and the energy attributable to frequencies higher than this represents only $10^{-5} \mathrm{~m}^{2} / \mathrm{Hz}$ for all sites in the average conditions during the deployment. Thus, at most, wave-blocking at the mouth may preclude high-frequency wind waves from entering the Bay, which are expected to make small contributions to the total wave energy in the Bay, including sites close to the mouth.

Waves that are not blocked may be steepened by opposing currents, an effect that increases the surface variance (wave height and energy density) but does not modify wave power (Dodet et al., 2013). However, we found the wave power spectrum $\bar{P}(f)$ followed similar patterns to the energy density spectrum across the four categories of tidal conditions, indicating that the loss in wave power for swell and infragravity waves during ebbing conditions was likely due to dissipation driven by the opposing flow - although wave steepening does not alter wave power in an inviscid model, the enhanced energy density can be expected to lead to more rapid dissipation of wave energy. This counter-current dissipation effect is most pronounced at S2, which is adjacent to the main tidal channel and most exposed to currents. Cumulative dissipation along the wave path will also be increased due to increased travel time during opposing currents. Waves may also shed energy through additional nonlinear wave-current interactions, which may be frequencydependent. Huang et al. (1972) analytically construct a dispersion relationship when a tidal current, $u$, is present. They suggest that, with tides entering an embayment from the ocean, ebbing tidal currents "spread" the energy in a spectral peak across a wider frequency band, whereas flooding tidal currents sharpen peaks into narrower bands. We do not see these effects in our spectra, however we found ebbing conditions increased energy in the wind wave band (between 0.25 and 0.7 $\mathrm{Hz}$, generally) for the sites farthest from the mouth (from S2 to S4).

\subsection{Beach Building}

The waves observed during our study were too small to move sediment and build their respective beaches (Sec. 3.4). The BEBs in Tomales Bay likely have relict morphologies created by prior high-energy events in winds and swells. Morphologies determined by prior high-energy events are common among BEBs and have been reported by authors including Costas et al. (2005), Fellowes et al. (2021), and Gallop et al. (2020a). If different particle sizes can be resuspended independently, then fine sediment may have been resuspended during wave conditions observed in this study. Visual observations of near-beach turbidity corroborates this phenomenon, but these fines are not contributing to beach building. For sites closer to the mouth (e.g. S2), swell-frequency energy dominated the spectrum and swell-driven bed stresses dominated during higher water levels. 
In contrast, infragravity waves contributed a large proportion of the total spectral energy during lower levels, but due to their small wave heights and long periods, $u_{b}$ and $\tau_{b}$ values remained below thresholds for sediment motion.

The distance between the sensor and the beach may be critical depending on the beach-fronting bathymetry. In our study, S4 was over 110 meters from the beach due to a low-slope fronting mudflat. Thus, low water levels at the sensor may represent conditions during which no waves reach the beach. Mid- to high-water tidal stages may be the only times during which locally-generated wind waves can reach the beach at S4. At lower water levels, these short, shallow waves are likely attenuated by the mudflats and fronting subtidal vegetation, as found in San Francisco Bay by Lacy and MacVean (2016).

Given the characteristic differences discussed in Section 3.1, data from S2 serves as a template of a sand-dominated near-channel beach in the Bay, and is close enough to the mouth to be influenced by swell-an "outer bay" beach. Data from S4, on the other hand, represents a model of a mudflat-fronted beach deep within the Bay, where effects of swell are absent and tidal currents are weak; at these "inner bay" beaches, wave energy is due to locally-generated wind waves. This inner/outer distinction in Tomales Bay is supported by hydrodynamic modeling in Gross and Stacey (2004) and sedimentation patterns detailed by Rooney and Smith (1999) and can be expected to be observed in other semi-enclosed bays where ocean waves are absent from an "inner bay".

At both S2 and S4, beach-building conditions most likely occur at high tide, because there is less attenuation of wave energy. For the outer-bay beach (S2), this permits more swell to enter the bay and impact the beach; for the inner-bay beach (S4), the same is true for locally-generated wind waves. Some beaches in Tomales Bay serve to protect low-lying back-barrier marshes, such as at Pita Beach and Indian Beach (Fig. 1), 5.3 and $13.5 \mathrm{~km}$ from the mouth, respectively, suggesting that beaches with back-barrier marshes can emerge in both swell-dominated and wind-wavedominated areas of the bay (i.e., outer bay and inner bay BEBs).

Sediment availability and the general geologic context also serve as strong controls on beach location and morphology (Gallop et al., 2020a). Broadly, Tomales Bay acts as a littoral-cell adjacent system of shoals with fluvial input from Walker Creek near the mouth and marine sediments extending as far as Hog Island (Johnson and Beeson, 2019); a deep sink in the central bay; and a second sediment supply via the Lagunitas Creek delta at the southern end of the Bay (Rooney and Smith, 1999). For beaches in central Tomales Bay, with no connection to the flood-tide or fluvial deltas, and only very small adjacent watersheds, available sediment may be limited to local input (i.e., shoreline erosion). The beach at Tomasini Point (S4) exhibits a high incidence of coarse pebbles, and may be undergoing winnowing during even mild winds at high tides (wind waves resuspend fines that are transported away by tidal currents). Some replacement of the fines may occur during floods or due to fluvial inputs, but resolving this question and others around sediment provenance requires additional work outside the scope of this study.

\section{Conclusions}

Waves that build beaches in estuaries and bays (BEBs) may enter through the mouth or be generated within the bay by local winds. Observations from mesotidal Tomales Bay, California, show that the dominance of locally-generated wind waves increased with distance from the mouth, consistent with a longer in-bay fetch for strong prevailing winds. In contrast, the influence of oceanic swell and infragravity waves did not extend beyond Seal Beach, $3.4 \mathrm{~km}$ from the mouth, separating the swell-influenced "outer bay" beaches from wind-wave dominated "inner bay" beaches. Hightide water levels allowed swell and infragravity waves to impact BEBs with less dissipation than low-tide conditions. At all sites in the bay, energy at frequencies $>0.4 \mathrm{~Hz}$ increased during ebbing currents, and energy was reduced across the entire spectrum during low-tide water levels. No wave events capable of moving the beach sediment at our sensor sites were observed during our study period, suggesting that diurnal winds and weak summer swells do not alter the morphology of the BEBs. Our study highlights the need to differentiate beach-building events by tidal stage 
in shallow bays and to determine the spatial range of influence by ocean-originating waves on embayed shorelines.

\section{Acknowledgments}

Numerous conversations and references to fuel this work were provided by Mark Stacey and Jessie Lacy. We are grateful to Robin Roettger, David Dann, and Sam Winter for their field work to install and maintain the sensors. AVC and JLL are grateful for support received through the Partnership Collaboration Award linking the University of Sydney with University of California Davis.

\section{References}

Anima RJ, Chin JL, Finlayson DP, McGann ML, Wong FL. Interferometric Sidescan Bathymetry, Sediment and Foraminiferal Analyses; a New Look at Tomales Bay, California; 2008.

Beach RA, Sternberg RW. Suspended sediment transport in the surf zone: Response to incident wave and longshore current interaction. Marine Geology. 1992 Nov; 108(3-4):275-294. https://linkinghub.elsevier.com/ retrieve/pii/002532279290201R, doi: 10.1016/0025-3227(92)90201-R.

Bertin X, de Bakker A, van Dongeren A, Coco G, André G, Ardhuin F, Bonneton P, Bouchette F, Castelle B, Crawford WC, Davidson M, Deen M, Dodet G, Guérin T, Inch K, Leckler F, McCall R, Muller H, Olabarrieta M, Roelvink D, et al. Infragravity waves: From driving mechanisms to impacts. Earth-Science Reviews. 2018 Feb; 177:774799. https://linkinghub.elsevier.com/retrieve/pii/S0012825217303239, doi: 10.1016/j.earscirev.2018.01.002.

Bishop CT, Donelan MA. Measuring waves with pressure transducers. Coastal Engineering. 1987 Nov; 11(4):309-328. https://linkinghub.elsevier.com/retrieve/pii/0378383987900317, doi: 10.1016/03783839(87)90031-7.

Chen Q, Madsen PA, Schäffer HA, Basco DR. Wave-current interaction based on an enhanced Boussinesq approach. Coastal Engineering. 1998 Mar; 33(1):11-39. https://linkinghub.elsevier.com/retrieve/pii/ S0378383997000343, doi: 10.1016/S0378-3839(97)00034-3.

Coastal Engineering Research Center. Shore Protection Manual Volume 1; 1984.

Collins Jl. Prediction of shallow-water spectra. Journal of Geophysical Research. 1972 May; 77(15):2693-2707. http://doi.wiley.com/10.1029/JC077i015p02693, doi: 10.1029/JC077i015p02693.

Costas S, Alejo I, Vila-Concejo A, Nombela MA. Persistence of storm-induced morphology on a modal lowenergy beach: A case study from NW-Iberian Peninsula. Marine Geology. 2005 Nov; 224(1-4):43-56. https: //linkinghub.elsevier.com/retrieve/pii/S0025322705002641, doi: 10.1016/j.margeo.2005.08.003.

Davidson MA, O'Hare TJ, George KJ. Tidal Modulation of Incident Wave Heights: Fact or Fiction? Journal of Coastal Research. 2008 Mar; 24(2B):151-159. http://www.bioone.org/doi/abs/10.2112/06-0754.1, doi: 10.2112/06-0754.1.

Dodet G, Bertin X, Bruneau N, Fortunato AB, Nahon A, Roland A. Wave-current interactions in a wavedominated tidal inlet. Journal of Geophysical Research: Oceans. 2013 Mar; 118(3):1587-1605. http://doi. wiley.com/10.1002/jgrc.20146, doi: 10.1002/jgrc.20146.

Eliot MJ, Travers A, Eliot I. Morphology of a Low-Energy Beach, Como Beach, Western Australia. Journal of Coastal Research. 2006 Jan; 221:63-77. http://www.bioone.org/doi/abs/10.2112/05A-0006.1, doi: 10.2112/05A-0006.1.

Ellis JT, Sherman DJ, Bauer BO. Depth Compensation for Pressure Transducer Measurements of Boat Wakes. Journal of Coastal Research. 2006; 1(39):6.

Fellowes TE, Vila-Concejo A, Gallop SL, Schosberg R, de Staercke V, Largier JL. Decadal shoreline erosion and recovery of beaches in modified and natural estuaries. Geomorphology. 2021 Oct; 390:107884. https://www. sciencedirect.com/science/article/pii/S0169555X21002920, doi: 10.1016/j.geomorph.2021.107884.

Foster-Martinez MR, Lacy JR, Ferner MC, Variano EA. Wave attenuation across a tidal marsh in San Francisco Bay. Coastal Engineering. 2018 Jun; 136:26-40. https://linkinghub.elsevier.com/retrieve/pii/ S0378383917305525, doi: 10.1016/j.coastaleng.2018.02.001. 
Gallop SL, Kennedy DM, Loureiro C, Naylor LA, Muñoz-Pérez JJ, Jackson DWT, Fellowes TE. Geologically controlled sandy beaches: Their geomorphology, morphodynamics and classification. Science of The Total Environment. 2020 Aug; 731:139123. https://linkinghub.elsevier.com/retrieve/pii/S0048969720326401, doi: 10.1016/j.scitotenv.2020.139123.

Gallop SL, Vila-Concejo A, Fellowes TE, Harley MD, Rahbani M, Largier JL. Wave direction shift triggered severe erosion of beaches in estuaries and bays with limited post-storm recovery. Earth Surface Processes and Landforms. 2020 Dec; 45(15):3854-3868. https://onlinelibrary.wiley.com/doi/10.1002/esp.5005, doi: 10.1002/esp.5005.

Gross ES, Stacey MT. Three-Dimensional Hydrodynamic Modeling of Tomales Bay, California. In: Estuarine and Coastal Modeling (2003) Monterey, California, United States: American Society of Civil Engineers; 2004. p. 646-666. http://ascelibrary.org/doi/10.1061/40734\%28145\%2940, doi: 10.1061/40734(145)40.

Huang NE, Chen DT, Tung CC. Interactions between Steady Non-Uniform Currents and Gravity Waves with Applications for Current Measurements. Journal of Physical Oceanography. 1972; 2:420-431.

Hughes MG, Aagaard T, Baldock TE, Power HE. Spectral signatures for swash on reflective, intermediate and dissipative beaches. Marine Geology. 2014 Sep; 355:88-97. https://linkinghub.elsevier.com/retrieve/ pii/S0025322714001492, doi: 10.1016/j.margeo.2014.05.015.

Jackson NL, Nordstrom KF, Eliot I, Masselink G. 'Low energy' sandy beaches in marine and estuarine environments: a review. Geomorphology. 2002 Nov; 48(1-3):147-162. https://linkinghub.elsevier.com/retrieve/pii/ S0169555X02001794, doi: 10.1016/S0169-555X(02)00179-4.

Johnson SY, Beeson JW. Shallow Structure and Geomorphology along the Offshore Northern San Andreas Fault, Tomales Point to Fort Ross, California. Bulletin of the Seismological Society of America. 2019 Jun; 109(3):833-854. https://pubs.geoscienceworld.org/ssa/bssa/article/109/3/833/569714/ Shallow-Structure-and-Geomorphology-along-the, doi: 10.1785/0120180158.

Lacy JR, MacVean LJ. Wave attenuation in the shallows of San Francisco Bay. Coastal Engineering. 2016 Aug; 114:159-168. https://linkinghub.elsevier.com/retrieve/pii/S0378383916300369, doi: 10.1016/j.coastaleng.2016.03.008.

Large WG, Pond S. Open Ocean Momentum Flux Measurements in Moderate to Strong Winds. Journal of Physical Oceanography. 1981; 11:324-336.

Madsen OS, Grant WD. The Threshold of Sediment Movement Under Oscillatory Waves: A Discussion. Journal of Sedimentary Petrology. 1975; 45:360-361.

Millero FJ, Chen CT, Bradshaw A, Schleicher K. A new high pressure equation of state for seawater. Deep-Sea Research. 1980; 27A:255-264.

NDBC, NDBC - Station 46013 Recent Data. National Buoy Data Center; 2020. https://www.ndbc.noaa.gov/ station_page.php?station $=46013$.

Nielsen P. Coastal Bottom Boundary Layers and Sediment Transport, vol. 4 of Advanced Series on Ocean Engineering. WORLD SCIENTIFIC; 1992. https://www.worldscientific.com/worldscibooks/10.1142/1269, doi: $10.1142 / 1269$.

NOAA, 9415020, Point Reyes CA | Datums - NOAA Tides \& Currents. National Oceanic and Atmospheric Administration; 2020. https://tidesandcurrents.noaa.gov/datums.html?datum=MLLW\&units=1\&epoch=0\&id= 9415020\&name $=$ Point + Reyes\&state $=$ CA.

Okihiro M, Guza RT. Infragravity energy modulation by tides. Journal of Geophysical Research. 1995; 100(C8):16143-16148.

Pereira L, Concejo AV, Trindade W. Tidal modulation. In: Sandy Beach Morphodynamics Elsevier; 2020.p. 87-101. https://linkinghub.elsevier.com/retrieve/pii/B9780081029275000059, doi: 10.1016/B978-0-08-102927-5.000059.

Rooney JJ, Smith SV. Watershed Landuse and Bay Sedimentation. Journal of Coastal Research. 1999; 15:8.

Talke SA, Stacey MT. The influence of oceanic swell on flows over an estuarine intertidal mudflat in San Francisco Bay. Estuarine, Coastal and Shelf Science. 2003 Nov; 58(3):541-554. https://linkinghub.elsevier.com/ retrieve/pii/S027277140300132X, doi: 10.1016/S0272-7714(03)00132-X. 
601

602

603

604

605

606

610

611

612

613

614

615

616

617

Trindade W, Pereira LCC, Vila-Concejo A. Tidal Modulation of Moderate Wave Energy on a Sandy Tidal Flat on the Macrotidal Amazon Littoral. Journal of Coastal Research. 2016 Mar; 75(sp1):487-491. http:/ /www. bioone. org/doi/10.2112/SI75-098.1, doi: 10.2112/SI75-098.1.

Vila-Concejo A, Gallop SL, Largier JL. 15 - Sandy beaches in estuaries and bays. In: Jackson DWT, Short AD, editors. Sandy Beach Morphodynamics Elsevier; 2020.p. 343-362. https://www.sciencedirect.com/science/article/ pii/B9780081029275000151, doi: 10.1016/B978-0-08-102927-5.00015-1.

Wentworth CK. A Scale of Grade and Class Terms for Clastic Sediments. The Journal of Geology. 1922; 30(5):377-392. http://www.jstor.org/stable/30063207.

Wiberg PL, Sherwood CR. Calculating wave-generated bottom orbital velocities from surface-wave parameters. Computers \& Geosciences. 2008 Oct; 34(10):1243-1262. https://linkinghub.elsevier.com/retrieve/pii/ S009830040800054X, doi: 10.1016/j.cageo.2008.02.010.

Williams ME, Stacey MT. Tidally discontinuous ocean forcing in bar-built estuaries: The interaction of tides, infragravity motions, and frictional control. Journal of Geophysical Research: Oceans. 2016 Jan; 121(1):571585. https://onlinelibrary.wiley.com/doi/abs/10.1002/2015JC011166, doi: 10.1002/2015JC011166.

Zhu L, Chen Q, Wang H, Capurso W, Niemoczynski L, Hu K, Snedden G. Field Observations of Wind Waves in Upper Delaware Bay with Living Shorelines. Estuaries and Coasts. 2020 Jun; 43(4):739-755. http://link. springer.com/10.1007/s12237-019-00670-7, doi: 10.1007/s12237-019-00670-7. 